\title{
Comunicação ambiental: estratégias de mobilização socioparticipativa para educação, informação e integração da rede socioambiental APA SUL RMBH
}

\author{
Environmental Communication: Social and \\ Participatory Mobilization Strategies for Education, \\ Information and Integration of the \\ Socio-Environmental Network APA SUL RMBH
}

\author{
Miguel Ângelo ANDRADE* \\ André Rocha FRANCO** \\ Rodrigo Gomes TINOCO ${ }^{* * *}$ \\ Denise de Castro PEREIRA ${ }^{* * * *}$ \\ Ricardo Ferreira RIBEIRO*****
}

\begin{abstract}
RESUMO
O objetivo deste artigo é introduzir e analisar os modelos de comunicação utilizados na estruturação da Rede Socioambiental no território da unidade de conservação da APA SUL RMBH, um ambiente que envolve questões polêmicas e interesses econômicos. Tais modelos almejam estabelecer diálogos e compartilhar informações acerca dessa região de modo intersetorial, participativo, igualitário e dinâmico, enfatizando o caráter mobilizatório dos processos comunicativos. A definição de objetivos comuns, a problematização participativa, a definição dos atores sociais e seus papéis, bem como o planejamento para a maior eficiência do processo, emergem como estratégias de mobilização que se estruturam "com" e não "para" a sociedade. Nesse contexto, o usufruto e a consolidação de ferramentas de comunicação efetivas, como, por exemplo, fóruns permanentes de debates, cartilha informacional, pesquisas sociais, formação de agentes locais inseridos em um modelo estrutural virtual e de alta tecnologia - Portal (ou Site) da Rede Socioambiental APA SUL RMBH - tornam-se base para a convocação dos propósitos
\end{abstract}

\footnotetext{
*Biólogo, Mestre em Tratamento da Informação Espacial - Geografia, pela Pontifícia Universidade Católica de Minas Gerais. Professor e coordenador do Curso de Ciências Biológicas da Pontifícia Universidade Católica de Minas Gerais. Email: miguelandrade@pucminas.br

"* Bolsista de iniciação científica, atuação no "Projeto de Educação Ambiental para os Recursos Hídricos do Parauninha: Comunidades Ribeirinhas como Cidadãos Promotores de Sustentabilidade na Região do Parque Estadual da Serra do Intendente". Email: andrefrancobio@yahoo.com.br

${ }^{* * *}$ Biólogo e Gestor Ambiental pela Pontifícia Universidade Católica de Minas Gerais.Pontifícia Universidade Católica de Minas Gerais. Email: tinocopuc@gmail.com

***** Doutora em Sociologia pela Universidade Federal do Rio de Janeiro - IFCS/PPGSA._Professora Adjunta III da Pontifícia Universidade Católica de Minas Gerais. Email: dpereira@pucminas.br

****** Mestre em Sociologia pela Universidade Federal de Minas Gerais e doutorado em Desenvolvimento, Agricultura e Sociedade pela Universidade Federal Rural do Rio de Janeiro. Professor Adjunto da Pontifícia Universidade Católica de Minas Gerais, do Mestrado de Turismo e Meio Ambiente e do Mestrado Profissional em Gestão Social, Educação e Desenvolvimento Local do Centro Universitário UMA. Email: ricrib@uai.com.br
} 
comuns e o estabelecimento de redes sociais. A tecedura e o cruzamento dessas relações delineiam, então, um conjunto interligado de fatores complementares que regem a mobilização social nesse espaço de sociobiodiversidade.

Palavras-chave: comunicação ambiental; mobilização socioparticipativa; redes sociais.

\begin{abstract}
This article aims at introducing and analyzing communication models used in the socio-environmental network APA SUL RMBH, an environmentally sensitive area in which polemic issues and economic interests are involved. These models provide inter-sectorial, participative, egalitarian and dynamic dialogues and information in order to put emphasis on the mobilization that characterizes the communicative process. The definition of common purposes, social actors and their roles, the active participation of all members of the community as well as the planning for more efficiency in the process reveal strategies of mobilization which structure themselves "with" and not "for" society. In this context, the usufruct and the consolidation of effective communication tools like, for example, permanent forums for debates, informational booklet, social research, training of local staff within a virtual and high-tech structural model - Portal (or Site) of the socio-environmental network APA SUL RMBH - have become a foundation for the convocation of common purposes and the establishment of social networks. Thus, the weaving and the crossing of these relationships outline an interconnected set of complementary factors that govern social mobilization in this socio-biodiversity area.
\end{abstract}

Key-words: environmental communication; social and participatory mobilization; social networks.

\section{O projeto da rede socioambiental APASUL RMBH}

O projeto de pesquisa e extensão intitulado "Projeto Estruturante da Rede de Extensão Socioambiental em Regiões Mínero-Metalúrgicas: a APA SUL, seu mosaico de unidades de conservação e as comunidades do entorno" tem o objetivo de estruturar e implementar uma rede de extensão socioambiental em regiões mínero-metalúrgicas do Estado de Minas Gerais, visando ao planejamento territorial e ambiental da Área de Proteção Ambiental Sul da Região Metropolitana de Belo Horizonte - APA SUL RMBH. O enfoque básico se fundamentou em dois elementos estruturantes: o das Unidades de Conservação - UC - instituídas, incluindo as de Proteção Integral e as de Uso Sustentável, e as comunidades residentes no entorno imediato dessas áreas protegidas.

O projeto pretendeu avançar na estratégia de estruturação da Rede Socioambiental a partir de espaços de conservação da biodiversidade, da cultura e da paisagem, tomando como referência distintas escalas de tempo e de espaço para o planejamento, em que se destaca a Reserva da Biosfera da Serra do Espinhaço (RBSE) (Figura 1), compreendendo a APA SUL RMBH, esta composta pelas Unidades de Conservação (UCs) e Áreas de Proteção Especial Estaduais
(APEs). Compondo um mosaico, esse território mostra-se adequado como objeto de estudo e demonstra potencial de projeção para outros espaços que tenham conformação semelhante, considerando a diversidade de características e a complexidade dessa unidade de planejamento.

AAPA SUL RMBH (Figura 2) engloba 13 municípios na parte Sul da RMBH e registra, atualmente, mais de duas dezenas de UCs, englobando as categorias Reserva Particular do Patrimônio Natural, Áreas de Proteção Especial, Parques Municipais e Estaduais, Estações Ecológicas, além das Áreas de Preservação Permanente. Essa diversidade reforça a adequação da região como referência para o estudo das relações entre a gestão da UC e o desenvolvimento socioeconômico, tendo como componentes comunidades que habitam a APA SUL RMBH, cujas características, diversificadas quanto aos aspectos culturais, econômicos, políticos e tecnológicos, associadas às suas estruturas paisagísticas organizadas pela sua geomorfologia e pela sua biodiversidade, compõem um cenário único em relação às suas potencialidades e também pelas diversas fontes de conflitos de várias ordens. Tal dialética exige um modelo de comunicação que atenda às diversas vozes inseridas nesse contexto. 


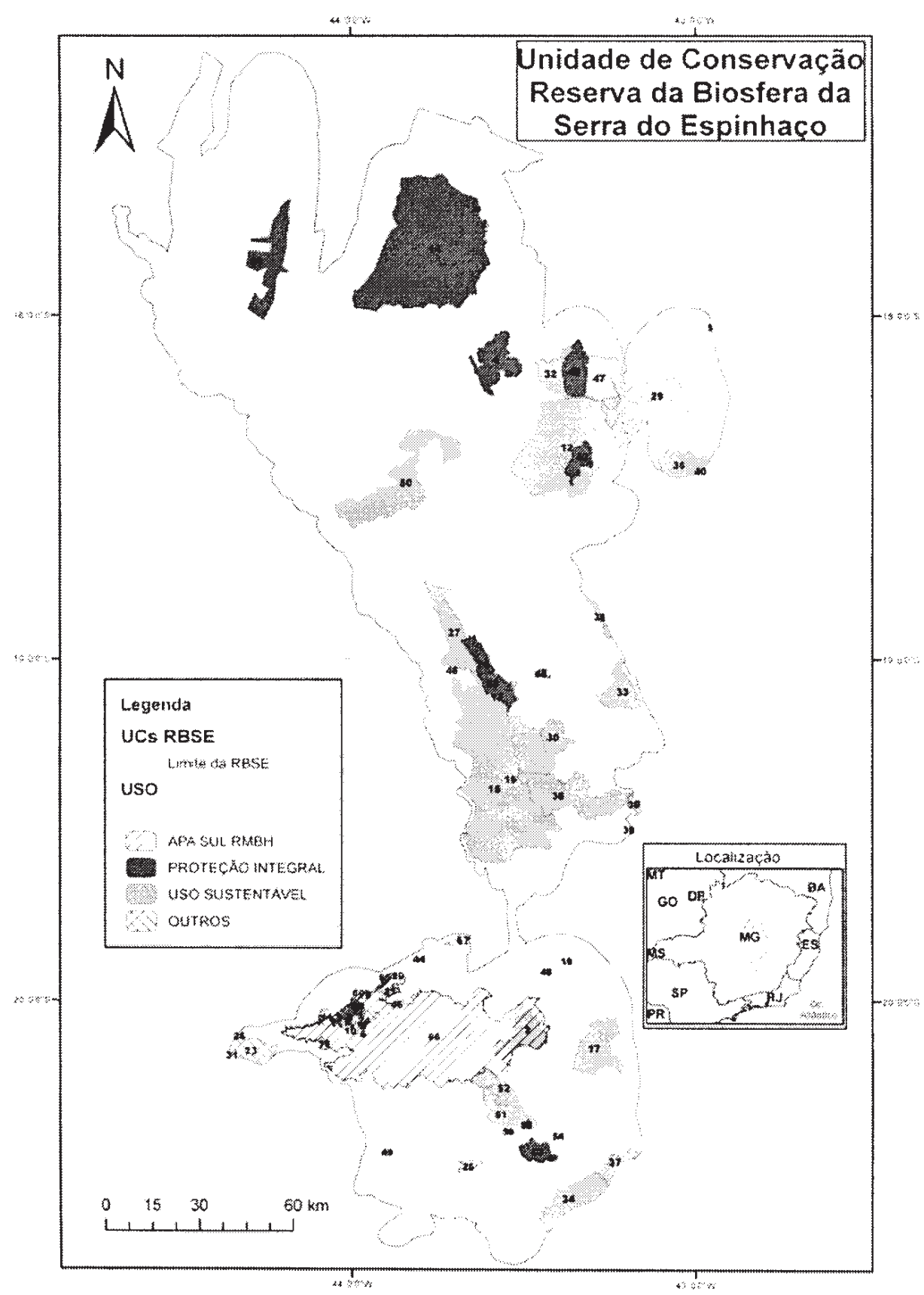

FIGURA 1 - MAPA DAS UNIDADES DE CONSERVAÇÃO DA RESERVA DA BIOSFERA DA SERRA DO ESPINHAÇO. FONTE: ELABORAÇÃO DO PROJETO FAPEMIG CRA 2350/07 - REDE SOCIOAMBIENTAL APA SUL RMBH. 


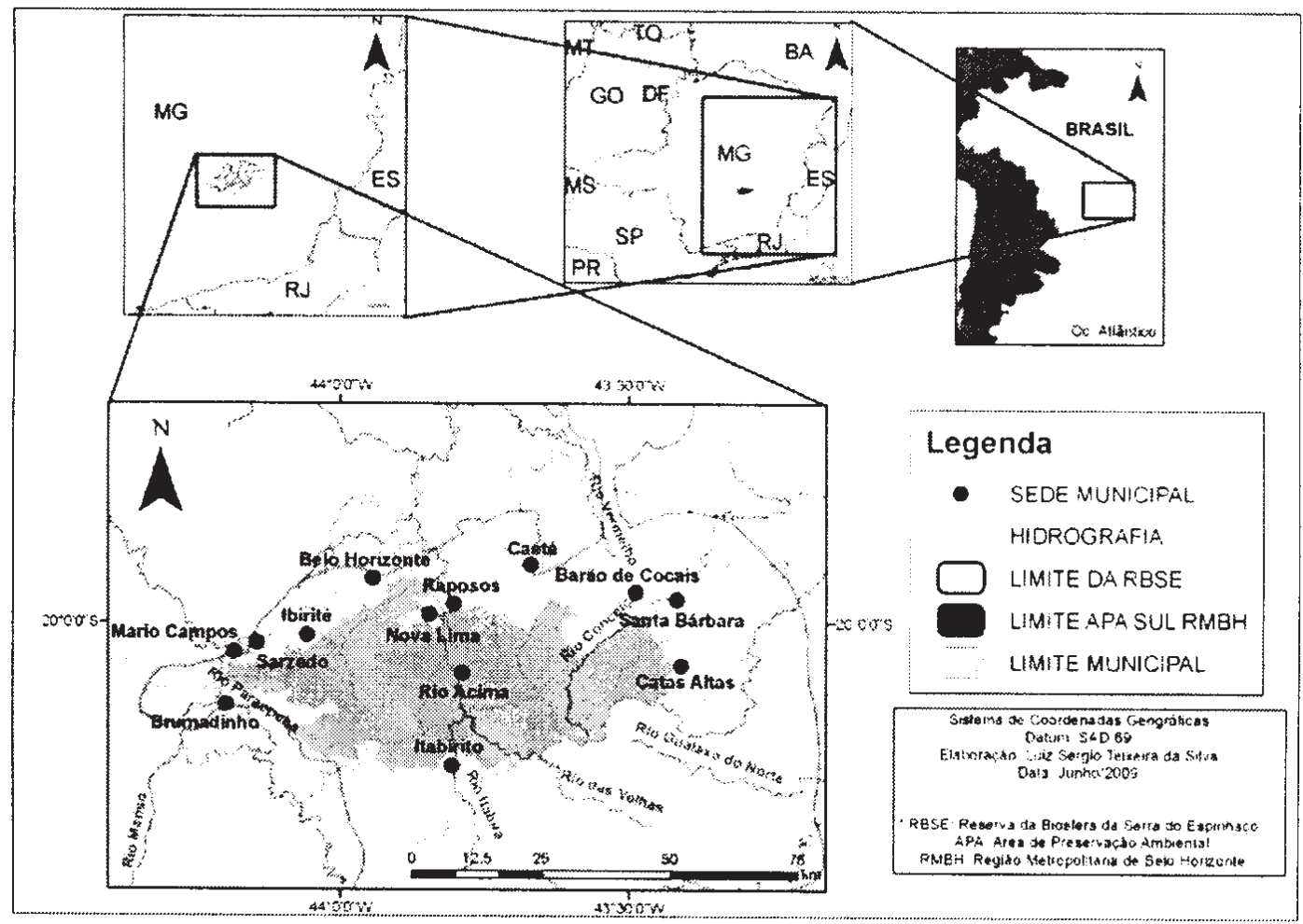

FIGURA 2 - MAPA DE LOCALIZAÇÃO DA APA SUL RMBH. FONTE: IBGE (2005).

A partir dessa multiplicidade de atores, o projeto informacional da Rede Socioambiental APA SUL RMBH cria e apresenta elementos de mídia para a comunicação ambiental, site e Cartilha da Rede Socioambiental da APA SUL RMBH. Os propósitos do projeto reúnem a ideia de conexão por meio do diálogo, do encurtamento de distâncias e de intercâmbios presenciais e virtuais com o fortalecimento e mobilização das esferas envolvidas: sociedade civil, universidades, empresas privadas, poder público em todas as esferas e, de modo especial, os governos locais, no processo de gestão ambiental compartilhada e participativa do território.

\section{Conflitos e finalidades da comunicação ambiental: implicações na Rede Socioambiental APA SUL RMBH}

A comunicação ambiental, conforme afirma Campos (2007), pode ser entendida como o processo de compartilhar informações sobre temas ambientais entre organizações e suas partes interessadas, visando construir confiança, credibilidade, parcerias e cooperação para conscientizar os envolvidos e, então, utilizar as informações no processo decisório.

Segundo a norma ISO 14063 (2006), que define os princípios, a política, as estratégias e as atividades relacionadas à comunicação ambiental, esse processo de transmissão e intercâmbio de informações deve, inicialmente, analisar e estabelecer objetivos, identificar partes interessadas e considerar os recursos necessários para atingir a sua maior eficiência. A comunicação ambiental, como denota Moreira (2001), torna-se, então, uma estratégia importante nos processos que regem tanto as relações corporativas intersetoriais e a comunicação com os públicos externo e interno, bem como a obtenção de informações úteis à tomada de decisão em gestão ambiental participativa. Os planejamentos estratégicos desses modelos institucionais são moldados, sobretudo, por prazos e metas bem definidos, 
a partir das perspectivas mercadológica e econômica. Tais perfis se estruturam almejando uma maior penetração e aceitabilidade de licenças ambientais, com o intuito de aproximar os processos produtivos dos ambientes de consumo.

Em alguns setores sociais, as abordagens se distanciam dessa amarra temporal. Retomam, no entanto, discussões a partir de demandas da organização social de onde surgem as necessidades de comunicação para a solução de problemas. Assim, a mobilização social permeia os movimentos de organização, tendo em vista a definição de propósitos comuns que serão objetos de debate e promoção social.

A escala temporal, portanto, difere daquela pautada pelo mercado. Emergem, assim, figuras e processos que constroem uma lógica social mais diversa e flexível quanto aos atores envolvidos, objetos de discussão e estratégias de comunicação mais efetivas para a solução de problemas. É nesse contexto que a sociedade lança mão da comunicação social e suas estratégias para dinamizar as redes sociais. Para entender tal dinâmica, torna-se fundamental a abordagem de Toro e Werneck (2004), que nos orienta para a definição de objetivos comuns, a problematização participativa, a definição dos atores sociais e seus papéis, bem como o planejamento para a maior eficiência do processo. $\mathrm{O}$ movimento aqui se estrutura "com" e não "para" a sociedade. Para os mesmos autores (2004), a mobilização social ocorre "quando um grupo de pessoas, uma comunidade ou uma sociedade decide e age com um objetivo comum, buscando, quotidianamente, resultados decididos e desejados por todos" (TORO; WERNECK, 2004, p. 13).

Outra questão que provoca a maior eficiência em processos participativos é a dinâmica de autonomia e continuidade do movimento: ser legítimo, horizontalizado e de dentro para fora, ou seja, parte de demandas internas de espaços sociais.

Em consonância com isso, o ato de comunicar se mostra como um método eficaz, no qual os atores envolvidos no processo e nas ações socioambientais possam relatar sobre as iniciativas, os saberes tradicionais locais e as propostas presentes e futuras do público envolvido no processo comunicativo. Essas informações se referem às lacunas e perspectivas do cotidiano de cada indivíduo e à busca pela efetivação de resultados esperados, baseada em um processo potencializador da transmissão de informação multissetorial, de educação e de integração social.

Quando se remete à comunicação ambiental, Goothuzem (2009) atribui-lhe uma finalidade definida e uma extre- ma relevância, confirmando a necessidade de mobilização e participação, envolvida com uma mudança de atitudes e de comportamentos. Considera-se que a conscientização ou o conhecimento levarão a uma decisão sobre atos que podem ser prejudiciais ao meio ambiente, a qual, por sua vez, conduzirá a novos hábitos, sem que ocorram mudanças significativas no contexto tradicional em que esse público esteja inserido.

A utilização das ferramentas de comunicação, contudo, não deve se limitar à mera transmissão de informações e sim abordar - e até sugerir - os meios pelos quais esses objetivos podem ser alcançados. Nesse contexto, a função do emprego da informação e sua relação com a comunicação pode ser explicada da seguinte forma:

Comunicação não pode ser simplesmente confundida com informação, pois informação pode ser transmitida mecanicamente e até de forma impessoal. Entretanto, informação é uma excelente matéria-prima para a comunicação, pois quem está informado está bem mais preparado para o diálogo, está em melhores condições para entender e confiar no interlocutor, ainda mais se houver a confiança de que o interlocutor passou todas as informações necessárias e não apenas as que lhe interessavam, pois, nesse caso, ainda haverá manipulação e não uma atitude nobre com o intuito de convocar o outro para o diálogo ou ação cooperativa e comunitária (SILVA, 1997, p. 29).

Esse nível de abordagem costuma se confrontar com os dogmas usados de forma cotidiana na comunicação relacionada ao meio ambiente. Esses são derivados do período em que a defesa do meio ambiente era antes uma causa do que uma necessidade, sendo que tais dogmas ainda continuam permeando a disseminação de conhecimento sobre a relação do homem com o meio ambiente. Contudo, conforme Goothuzem (2009), para uma comunicação ambiental mais efetiva, que leve a uma real modificação de atitudes e comportamentos, é preciso deixar os dogmas de lado e investir no conhecimento local sobre o ambiente em que se vive.

Mais uma vez, a mobilização social preconiza o envolvimento e a valorização desta escala geográfica local, facilitando o intercâmbio de intenções e de conhecimento para as discussões das questões ambientais. Assim, a definição das unidades de planejamento é, também, estratégica para os recortes de objetivos. 
Pensando nisto, é indispensável uma definição exata de onde se quer tocar, ou seja, a definição do modo em que os objetos e atores sociais se dão no espaço. Assim, esse recorte físico é necessário, evitando a não obtenção de resultados compartilhados com a sociedade local. Qual o tamanho e em qual território se quer atuar? Qual a composição de suas realidades complexas? Qual o nível de informação e conhecimento que se tem e se quer construir nesse território?

O engajamento de atores sociais que, em geral, têm um vínculo e um enraizamento local muito fortes, assim como um compromisso ético com as populações e o território onde desenvolvem suas atividades em redes que transcendem a sua escala de atuação e de poder de influência, é um dado novo e sedento de atuações diversas. Nesse contexto, surge a abordagem de estruturação de uma rede socioambiental no território da unidade de conservação da APA SUL $\mathrm{RMBH}$, um ambiente permeado de questões polêmicas e, muitas vezes, simplificadas pelos interesses econômicos.

Diante da discussão de políticas públicas de inclusão da sociedade nos processos decisórios de gestão desse território, estipula-se, como referência, o caminho de valorização de iniciativas convergentes para a discussão. Fóruns de debates, pesquisas sociais, formação de agentes locais e construção de meios de comunicação são base para a convocação dos propósitos comuns que regem a mobilização social nesse espaço de sociobiodiversidade.

Quando se fala em mobilização da sociedade para a questão ambiental, Rabelo (2003) exprime que os maiores avanços só podem ser alcançados mediante o diálogo entre as partes, comunicadores e ambientalistas, com práticas e relatos mais centrados nos processos do que nos instrumentos, nos sentidos mais do que nos conteúdos. É preciso, conclui, despertar a corresponsabilidade pelo meio ambiente.

Pretende-se, com esses relatos, consolidar, a partir do estabelecimento da Rede Socioambiental APA SUL RMBH, discussões acerca das questões políticas, socioambientais, culturais e econômicas. As metas a serem alcançadas estão baseadas na elaboração de ações corretivas de melhoria contínua e de reconhecimento e valorização das potencialidades e boas práticas socioambientais, envolvendo governos locais, empresas e sociedade civil no cenário tão diverso que envolve os metros quadrados da Área de Proteção Ambiental Sul da Região Metropolitana de Minas Gerais.

É nesse cenário que surge a necessidade do estabelecimento de um modelo de comunicação capaz de alcançar um público de massa, que sirva de instrumento pedagógico e didático e que desperte interesse, mantendo a qualidade do conteúdo e transmitindo a esse público a real situação do meio ambiente em uma perspectiva histórica e considerando suas implicações sociais e relacionais.

A forma organizada, mensurável, na perspectiva qualitativa da efetividade desse modelo, deve pautar-se pelo rigor científico e técnico, perpassando pelo caráter participativo e democrático, demonstrando a capacidade de adaptação e replicação desse modelo. As redes sociais, apoiadas nos instrumentos de comunicação, são carentes de modelos que orientem, cada qual, as realidades dessas redes, a implementação da comunicação mais efetiva e eficiente entre os atores que as animam.

A comunicação ambiental, de acordo com Elhajji et al. (2008), abre espaço para a aplicação de uma técnica de comunicação especializada em assuntos ambientais cujo desenvolvimento poderá tornar claras, à população em geral, informações referentes ao meio ambiente que estão inseridas num contexto complexo, caracterizado pela interdisciplinaridade e pelo uso de termos científicos específicos. Por outro lado, a ciência tem lançado mão dos saberes tradicionais e interpretado os arranjos sociais de redes organizadas.

Berna (2002) comprova essa lacuna do contexto ambiental ao afirmar que, apesar de existir uma grande quantidade de informações disponíveis sobre meio ambiente, elas se encontram dispersas e pouco sistematizadas, prejudicando o estabelecimento de parcerias e mesmo a mobilização da cidadania ambiental. Os diferentes atores envolvidos na tarefa de democratizar a informação ambiental, embora demonstrem grande disposição para troca de experiências, ainda têm pouco conhecimento sobre as atividades de seus pares.

Rabelo (2003) acrescenta, ainda, que há uma multiplicidade de informações relevantes sobre conservação e preservação que podem fundamentar uma decisão, mas que ainda não foram divulgadas (uso racional de água, licenciamento ambiental - Áreas de Preservação Permanente e reservas legais, poluição) ou o foram de maneira inadequada à compreensão. Além disso, a ciência possui uma linguagem muito técnica - na maioria das vezes só entendida por seus pares -, o que colabora ainda mais para excluir a sociedade de seu entendimento.

A perspectiva, então, é a delineação de uma proposta de comunicação em que todos os segmentos da sociedade sejam ouvidos e possam relatar suas reais condições de vida e suas propostas para o futuro, visando à construção 
de uma malha organizacional robusta, multilateral e atuante, capaz de elevar as potencialidades institucionais e alcançar os objetivos e metas de um processo permanente de transformação da realidade. Mas, conforme Valarelli (2001):

A capacidade de produzir mudanças nas relações sociais está muito além da capacidade de uma organização. $\mathrm{Na}$ visão corrente, é como se uma organização pudesse conceber um plano de trabalho que gerasse mudanças significativas nas relações sociais, a ponto de serem mensuradas. É necessário se pensar o processo de mudança das relações sociais como produto não de uma organização, mas de um campo, de um conjunto de organizações (VALARELLI, 2001, p. 2).

\section{A comunicação como instrumento de informação e educação}

Pichelli e Suzina (2005) denotam que a humanidade vive hoje o que se costuma chamar de "Sociedade do Conhecimento", caracterizada tanto por uma quantidade historicamente inigualável de informações sendo produzidas e disponibilizadas quanto pela desigualdade no acesso a esses conteúdos. Tal barreira pode ser ocasionada por limites tecnológicos, educacionais e, também, pela falta de adequação de algumas mensagens aos seus públicos de interesse ou mesmo ao cidadão comum.

As tecnologias da comunicação e informação, segundo Silva (2006), coincidem com a luta por uma educação melhor, nem sempre de maneira que beneficie todas as classes e estratos sociais. A organização da tecnologia em favor de maior igualdade, inclusão e acesso não está absolutamente garantida, mas dependerá, em grande medida, da mobilização de segmentos governamentais e empresariais, de educadores e comunidades, exigindo que a tecnologia seja usada de maneira que atenda aos interesses da educação para todos.

Nesse contexto, a educação objetiva, como indicado por Santos et al. (2008), a transformação do indivíduo no contexto social, pois amplia saberes, constrói a cidadania, estimula a continuidade e a replicação de seus propósitos, fundamenta costumes e culturas, preparando o indivíduo para ser um cidadão consciente, tendo em vista que as ações pedagógicas contribuem para a formação ética e política da sociedade. É preciso analisar que a educação (com ações pedagógicas) desempenha uma função social transformadora e emancipadora, que possibilita a interação entre as diversidades e adversidades, contribuindo decisivamente com o crescimento mútuo dos seres e a valorização das diferenças.

A educação ambiental, inserida em toda essa conjuntura instrucional, necessita de ferramentas e técnicas mobilizadoras e comunicativas que possam apresentar e esclarecer os propósitos de todo o processo educativo. Os meios de comunicação, então, precisam estar preparados para fazer inter-relações entre os mais diversos assuntos e o meio ambiente, mostrando à população como o tema está imbricado em tudo aquilo que afeta a sua vida.

Jacobi (2000) afirma que um dos fatores que explica a pouca aderência do discurso ambiental na sociedade é, sem dúvida, o isolamento das organizações ambientalistas dos outros movimentos sociais, uma vez que priorizavam em seu discurso a necessidade de garantir a qualidade ambiental, ignorando as demais demandas sociais.

Para uma real efetividade, o processo educativo, adjacente à utilização de metodologias e técnicas de comunicação e informação eficientes, necessita ser prolongado e replicado, favorecendo a consolidação e o fortalecimento de interações socioambientais, a possibilidade da afirmação de autonomia dos atores envolvidos e a perspectiva de prosseguimento e reedição dos fatores relacionados à educação e à comunicação ambiental.

Baseado na perspectiva de continuidade de um processo educativo, Faria (2000) expõe que o processo de aprender é um momento de descoberta. O aprendizado verdadeiro gera, em essência, a descoberta de "como aprender" e a vontade de continuar aprendendo e descobrindo coisas novas. Em outras palavras, quando se planeja a realização de um processo educativo, é preciso prever continuidade. É indispensável que o ato educacional gere um continuum, um movimento, uma vontade - e um caminho - para prosseguir.

Soares (2005) propõe, todavia,

[...] que os profissionais de educação deem um passo a mais: que utilizem os equipamentos dos meios de comunicação do mesmo modo como são utilizados o giz, a lousa, o lápis e o caderno; que a esses se misturem microfones, gravadores, câmeras fotográficas e de vídeo, computadores, aparelhos de tevê, rádio, caixas de som e cabos, cenários, trilhas sonoras, entre outros; que façam deles instrumentos de trabalho, objetos de manipulação, 
meios de produção dos saberes essenciais para construir uma sociedade de pessoas autônomas, ativas e realmente comprometidas consigo mesmas, com os outros e com todo o meio ambiente que as integra (SOARES, 2005, p. 3).

Nesse contexto, o projeto da Rede Socioambiental APA SUL RMBH busca viabilizar a elaboração e a aplicação de um conjunto de materiais e métodos que, de maneira gradual e sem descuidar da técnica, objetiva transpor e traduzir a essa coletividade uma gama de informações. A partir de tais informações, ao lado das práticas educacionais abrangentes, almeja-se incentivar a mobilização e a formação de atores sociais, possuidores de uma consciência cidadã e crítica e de um maior conhecimento e entendimento da conjuntura socioambiental em que a coletividade está inserida.

\section{A estruturação, o desenvolvimento e a socialização de redes de comunicação}

A autora Patrícia Mousinho (2007), integrante e facilitadora de diversas redes de educação ambiental, em seu texto "Redes", apresenta uma acepção múltipla de rede ao lembrar as várias facetas desse termo:

Fios que entrelaçados formam uma malha, que pode tanto se prestar à captura de peixes quanto a ser leito que (em) balança. Rede de pesca, rede de dormir. Além de redes de escolas, de serviços, de neurônios, de estradas, de telefonias. Sem nos esquecermos da rede do momento - a "grande Rede", como é chamada: a Internet (MOUSINHO, 2007, p. 301).

A busca por um conceito abrangente de rede nos remete a uma visão intrínseca de articulação, coesão, conexão entre coisas, lugares e pessoas. A tecedura dessas relações perpassa pela mistura, pelo entrelaçamento, pelo estabelecimento de redes sociais, delineando, assim, um conjunto interligado de fatores complementares.

Colaborando com uma explicação de rede, Castells (2000) formula uma definição enxuta: "um conjunto de nós interconectados". Já Inojosa (1999) se refere às redes como uma parceria que pode articular famílias, estados, organizações públicas e/ou privadas, pessoas físicas e/ou jurídicas, e, portanto, pode envolver e promover relações interpessoais, interorganizacionais, intergovernamentais e intersetoriais.

Amaral (2004) infere ainda que, embora não sejam uma proposta adequada a todo e qualquer tipo de organização, as redes são estruturas adequadas a objetivos de empoderamento e emancipação da sociedade.

Para tanto, o método que envolve o estabelecimento e a consolidação de redes comunicativas inclui encontros pessoais, organizações formais, encontros informais, material eletrônico e impresso, telefone, fax, correio, rádio, televisão, vídeo e comunicação mediada por computador.

As redes, inseridas em toda essa conjuntura tecnológica, inscrevem-se em uma lógica que demanda articulações e solidariedade, definição de objetivos comuns e redução de atritos e conflitos, considerando-se as características complexas e heterogêneas da sociedade. Nesse sentido, "as redes horizontalizam a articulação de demandas e se servem, crescentemente, das modernas tecnologias de informação para disseminar seus posicionamentos, denúncias e propostas, como referencial cada vez mais legítimo da presença de uma emergente sociedade civil global" (JACOBI, 2000).

Observando-se o cenário de fluxos na perspectiva de organismos críticos e reivindicantes dessa sociedade civil, é possível perceber que ambientes compartilhados favorecem convívios participativos e reciprocidades. Em distintas escalas e intensidades, as redes podem ativar conexões, simbólicas e solidárias, de sujeitos e atores coletivos, “cujas identidades vão se construindo num processo dialógico de identificações éticas e culturais, intercâmbios, negociações, resoluções de conflitos e de resistência aos mecanismos de exclusão sistêmica na globalização" (SCHERER-WARREN, 1998, p. 16-29).

Demonstrando outros benefícios da criação e efetivação de trabalhos em rede, Santos (2005, p. 156-157) comenta que uma das grandes vantagens da viabilização desses trabalhos é que a aprendizagem é constante, porquanto a dinâmica da rede implica reversão de práticas políticas tradicionais. Fazer parte de uma rede, atuando num espaço horizontalizado e plural, já constitui em si um grande aprendizado.

Segundo o mesmo autor, uma rede também pressupõe sua oxigenação constante e, à medida que sua mobilização e articulação avançam e seus processos se consolidam, aumenta a visão dos atores locais sobre suas fragilidades, potencialidades e possibilidades de intervenção social. Nesse contexto, o propósito dialético emerge no momento em que o intercâmbio de experiências e vivências é promovido, 
contribuindo para ampliar a capacidade e a oportunidade de participação das pessoas. Contudo, as organizações sociais nos espaços públicos não devem, necessariamente, estabelecer um processo formal de capacitação em que agentes externos irão oferecer seus conhecimentos aos que não os possuem, mas criar condições para que os conhecimentos das pessoas sejam valorizados e considerados nos espaços decisórios.

Os meios de comunicação não podem estar restritos a determinadas instituições e/ou organizações. O processo comunicativo deve ser soberano, a distribuição de informações equitativa e as mais diversificadas vozes ouvidas, sem levar em conta o estrato social e valorizando o modo individual de considerar determinados assuntos e questões. Moraes (2007, p. 4-5) corrobora esse ponto de vista, quando infere que os veículos de comunicação devem ser independentes do governo, do estado e das corporações, "relacionando-se especificamente a um projeto de transformação social" e que o trabalho desenvolvido por eles precisa ser "dialógico e democratizador", capaz de "difundir, coproduzir, organizar, articular, capacitar e reconstruir a memória, a identidade e a unidade na ação".

Reforçando os ideais dialógicos do projeto da Rede Socioambiental APA SUL RMBH, Berna (2002) exprime que cada veículo novo que surge na área ambiental cumpre uma importante função social, pois não só significa aumento de postos de trabalho para profissionais especializados, mas também se constitui num fator a mais de favorecimento do diálogo entre os diferentes setores da sociedade que precisam estabelecer parcerias entre si em direção a um desenvolvimento sustentável. Sem informação, não há diálogo, muito menos parcerias.

É por meio da delineação e consolidação dessas parcerias, portanto, que uma rede de comunicação se torna efetiva e capaz de articular e de integrar os diversos setores sociais envolvidos, fortalecendo as conexões desse espaço público. Santos (2005, p. 156), então, sugere que todo esse processo deve nos impor uma reflexão, sendo pertinente pensarmos que a viabilização do espaço público socioambiental pressupõe um processo de intensificação das interações entre os mais diversos atores, partindo de um contexto local para possibilidades mais amplas. O mesmo autor lembra também que, em caso de distâncias sociais e políticas abissais, a provocação da ação coletiva e a descoberta de pontos de convergência são cruciais.

John Downing (2002) percebe a importância da comunicação em rede para os movimentos em duas con- fluências: a interna, na medida em que facilita a mobilização e a organização, e a externa, como forma de alargar espaços de divulgação e de articulação de análises e ações. "Para os movimentos sociais, é crucial a interdependência dialética com veículos que possam reverberar suas propostas, geralmente ignoradas ou menosprezadas pela chamada grande mídia, com sua crônica desconfiança acerca dos pleitos e vozes comunitárias" (DOWNING, 2002, p. 65-67).

Pensar em rede, portanto, "é pensar nos fios que se entrelaçam, nos pontos e nós que se interligam, se comunicam, por onde flui e se espalha a informação. Nas relações que se estabelecem. Falar de redes é, em essência, falar de relações" (MOUSINHO, 2007, p. 301).

As redes possibilitam interações horizontais e a organização de instrumentos de pressão e abrem novos campos de possibilidades intersetoriais que transcendem suas fronteiras locais, integrando ativistas e militantes, associados num circuito amplificado de sociabilidade, de confiabilidade e de identidades ideológicas. Pode-se afirmar, então, que as redes interconectam instituições, práticas sociais diferenciadas e alargam o alcance das agendas (JACOBI, 2000, p. 4).

\section{O papel da rede virtual (internet) na integração social}

Com o intuito de buscar um significado seguro da expressão "integração social", recorremos às bem traçadas e delineadas lições de Ramos (2002, p. 162-163), que desenvolve o conceito em análise com fundamento na "Teoria da Integração Social" de Durkheim. Assim, somente existe integração social "com a frequência e intensidade de contatos sociais". Esses contatos implicam um comprometimento entre as pessoas e a ordem social, reforçando um sentimento de pertencimento perante a sociedade, afetando positivamente o indivíduo. Logo, é possível definir, mesmo que de maneira sumária, a integração social como uma gama de relações que habilitam o indivíduo a participar como sujeito ativo nas interações sociais.

Segundo Máximo (1999), a interatividade é, sem dúvida, uma das características mais marcantes da internet: o usuário é convidado a participar dessa interatividade no envio de mensagens pelo correio eletrônico (e-mail), na participação em listas eletrônicas ou fóruns de discussão em chats, ambientes multimídia e, até mesmo, no ato de 
navegar através de links de hipertexto nas páginas da web, visando à busca por informações. Ao criar um espaço para a circulação de informação, a rede das redes deu margem a uma multiplicação de formas de comunicação e de sociabilidade mediada pelo computador. Possibilitou-se, assim, a emergência do ciberespaço enquanto espaço virtual e mediatizado, onde tomam vida relações sociais que se expressam por meio da cibercultura.

No que diz respeito à internet, Moraes (2007, p. 1-2) a conceitua como um ecossistema digital caracterizado por arquitetura descentralizada, multiplicação de fontes de emissão, disponibilização ininterrupta de dados, sons e imagens, utilização simultânea e interações singulares. Esse cenário virtual, portanto, facilita a busca e o intercâmbio de conhecimento e informações provenientes de locais e vozes distintos, contemplando e fomentando o estabelecimento de redes comunicativas interligadas por meio do acesso à "rede".

Conforme Rheingold (1996), "a rede" é o termo informal que designa as redes de computadores interligadas, empregando a tecnologia de comunicação mediada por computador (CMC), a fim de associar pessoas de todo o mundo na forma de debates públicos e transmissão e recepção de informações.

$\mathrm{O}$ mesmo autor aponta que a $\mathrm{CMC}$ tem potencial para mudar a vidas das pessoas em três níveis distintos, mas fortemente interdependentes. Primeiramente, como sujeitos, uma vez que percepções, pensamentos e personalidades podem ser afetados pelo modo como é usado o meio de comunicação e vice-versa. $\mathrm{O}$ autor considera esse nível fundamental, pois a CMC "apela a certas necessidades intelectuais, materiais e emocionais que sentimos enquanto organismos vivos que somos" (RHEINGOLD, 1996, p. 26). O segundo nível compreende as relações interpessoais, amizades e comunidades, pois a CMC possibilita novas capacidades de comunicação multilateral ("muitos para muitos"). O terceiro nível, o nível político, deriva do anterior, caracterizado pelas relações sociais; assim, o autor entende que "a relevância política da CMC resulta da sua capacidade para desafiar o monopólio dos poderosos meios de comunicação detidos pela hierarquia política e talvez assim revitalizar a democracia dos cidadãos" (RHEINGOLD, 1996, p. 28).
Eduardo Galeano, ex-diretor de redação das célebres revistas Marcha (Uruguai) e Crisis (Argentina), salienta, em entrevista ${ }^{1}$, o lugar imprevisto e instigante que a internet vem ocupando no contexto de dramática concentração dos meios de comunicação e de oligopolização das indústrias culturais, ao dizer que: "a Internet realmente abriu espaços a vozes que agora encontram possibilidades de difusão incríveis" (GALEANO, 2005). O entrevistado sugere, também, que "a Internet virou um espaço que contém um pouco de tudo, que não é uma coisa só, mas que inclui muitas expressões, passando pela afirmação da boa energia da vida, da energia multiplicadora do melhor da vida, a liberdade, a vontade de justiça" (GALEANO, 2005).

Os meios de comunicação contemporâneos, adjacentes ao crescente processo de evolução e à revolução tecnológica, transformaram e vêm transformando, de modo contínuo e acelerado, a maneira como as pessoas se relacionam e interagem entre si, abrangendo gerações cada vez mais diversas, na questão dos costumes, metodologias de ensino e educação, integração social, lazer, línguas, linguagens e perspectivas e propostas para o futuro.

É nesse ambiente de novas tecnologias digitais e virtuais e interatividade, ecoando em todos os cantos da APA SUL RMBH, que a comunicação ambiental se torna cada vez mais difundida e, sobretudo, mais necessária para atender e preencher as lacunas de um processo comunicativo, dialógico e informativo abrangente e eficaz. O Projeto da Rede Socioambiental, então, sugeriu e consolidou a estruturação de um Portal como produto público e formalizador dos resultados da pesquisa e como espaço permanente de diálogo e intercâmbio de informações, assim como organizou uma Cartilha da Rede Socioambiental, que surge como um instrumento consultivo, informativo, pedagógico e de múltiplos acessos.

\section{O portal e a cartilha da Rede Socioambiental APA SUL RMBH: uma proposta de comunicação integrante}

(http://www.redeapasul.com.br)

O Projeto da Rede Socioambiental APA SUL RMBH efetivou a proposta de elaboração de um site de alta tec-

${ }^{1}$ Fazendo Média. Entrevista de Eduardo Galeano a Marcelo Salles, 28 de dezembro de 2005. Disponível em: <http://www.fazendomedia.com/novas/entrevista281205. htm>. 
nologia na internet para essa unidade de conservação. Os recursos de tecnologia de informação utilizados foram otimizados com o objetivo de incrementar e oportunizar o relacionamento entre a unidade de conservação e a sociedade, provendo acesso qualificado a informações disponíveis sobre a região e destacando a sua importância ambiental, econômica e cultural, entre outras dimensões. Atrelado à facilidade de atualização de dados, o site proporciona benefícios e agrega valores à APA SUL RMBH, passando a prestar serviços online de forma eficiente e prática, atraindo simpatizantes e colaboradores e obtendo maior apoio institucional.

A estruturação do site da Rede Socioambiental APA SUL RMBH visa atender as reais necessidades de um território permeado por questões polêmicas, que decorrem da coexistência de interesses e atividades diversificados, próprios de uma região com alta densidade demográfica, pressões para expansão urbana, intensivas atividades econômicas primárias, secundárias e terciárias, alto potencial de extração mineral e áreas prioritárias para conservação ambiental. Esse mosaico de realidades estimula o pensar socioambiental como um desafio que demanda estratégias de comunicação para dinamizar o relacionamento intersetorial.

Um site abrangente, interativo e de navegação leve, com informações completas e organizadas de forma a atender diferentes públicos, emerge como uma possibilidade de integração entre os diversos segmentos envolvidos com a APA. Tal modelo, além de ser uma exigência natural para aqueles que são referência em seus segmentos, atende as expectativas do internauta moderno, que busca eficiência da navegabilidade. Além disso, a estrutura do site deve estar coordenada com as estratégias desse Projeto Estruturante, do Programa MaB - UNESCO (RBSE) e da Rede Socioambiental APA SUL RMBH. A partir de tais estratégias articuladas, buscou-se traduzir a filosofia do Portal em um design coerente com sua imagem e, ao mesmo tempo, transmitir o conteúdo em uma linguagem acessível ao público heterogêneo que o acessa.

O projeto pretende beneficiar, já em momentos iniciais, os integrantes da Rede Socioambiental, o Conselho Consultivo da APA SUL RMBH, além da população do entorno de unidades de conservação inseridas na APA. Desde sua proposição, estabeleceram-se meios de intercâmbio com a Reserva da Biosfera da Serra do Espinhaço e com a gestão das unidades de conservação. A efetivação da proposta almeja beneficiar também pesquisadores, universidades, gestores governamentais e não governamentais, estudantes, educadores, empresários, comunidades, ambientalistas e a população em geral dos municípios integrantes da APA SUL RMBH. Enfim, o projeto aspira ampliar seu alcance para cidadãos do Brasil e do exterior interessados em contribuir com a conservação das riquezas naturais, obtendo informações, promovendo o desenvolvimento do pensar socioambiental, compartilhando soluções para os problemas coletivos e aprimorando técnicas e a logística dessa unidade de conservação. $O$ intuito é que o instrumento desperte e reforce o interesse de diversos setores da sociedade, mantendo a qualidade do conteúdo, transmitindo ao público situações que caracterizem o meio ambiente em uma perspectiva histórica, com suas implicações sociais e relacionais. Em síntese, que ele promova interpretações sobre a complexidade do cotidiano a partir de uma visão sistêmica.

\section{Objetivos do site da Rede Socioambiental APA SUL RMBH}

Os objetivos centrais do sistema de comunicação da Rede envolvem a disponibilização de materiais virtuais e impressos, no intuito de atingir a população que carece de tecnologias da informação. Nesse sentido, foram produzidos: o site, que, gradativamente, deve se expandir para consolidar o site da Rede Socioambiental APA SUL RMBH; a Cartilha sobre a unidade de conservação central deste estudo, a APA Sul; e três cartilhas abordando a relação das UCs com as comunidades pesquisadas, como instrumento de devolução de dados obtidos via DPR. Neste artigo, a ênfase será dada ao site e à Cartilha APA SUL RMBH Diversidade e Áreas Protegidas.

Os objetivos do sistema de comunicação, definidos segundo o Projeto Estruturante da Rede, são assim expressos:

- interconectar ações e projetos governamentais, científicos, comunitários e do setor produtivo de modo a potencializar conhecimentos e ações em favor da sustentabilidade da Área;

- apresentar o processo de criação e gestão da APA SUL RMBH, bem como criar um canal de apoio à comunicação interinstitucional dos segmentos envolvidos: conselheiros e comunidades inseridas na APA, parceiros, redes, programas nacionais e internacionais de cooperação técnica, dentre outros; 
- criar um canal de divulgação de informações, estudos, conhecimentos científicos e saberes tradicionais da APA SUL RMBH, por meio da transposição do banco de dados de modo virtual;

- explorar as características que possam gerar benefícios para a APA SUL RMBH, ajudando-a a se fixar como uma importante unidade de planejamento e gestão territorial, com destaque aos aspectos culturais, ecológicos, tecnológicos e de infraestrutura;

- apoiar a implementação da Rede Socioambiental e do Fórum Socioambiental Permanente das Comunidades da APA SUL RMBH;

- criar o Sistema de Informação Socioambiental e Econômico Integrado da APA SUL RMBH, com as atribuições de produzir e receber dados das instituições parceiras e disponibilizar esses dados;

- incentivar e expor as ações desenvolvidas pelos demais subprojetos (Criação do Sistema de Informação Socioambiental da APA SUL RMBH, Formação de Agentes de Desenvolvimento Local, Implementação da Rede Social APA SUL RMBH e do Fórum Socioambiental Permanente APA SUL $\mathrm{RMBH}$;

- disponibilizar as informações contidas no site, de forma resumida, em um formato impresso (Cartilha), alcançando, assim, comunidades/esferas sociais que não possuem acesso à internet.

Os objetivos a seguir referem-se à Cartilha, relacionando o seu caráter pedagógico e as possibilidades de disseminação do conhecimento em meio físico ou impresso, para facilitar o acesso a determinados públicos:

- disponibilizar as informações contidas no site, de forma resumida, em um formato impresso (Cartilha), alcançando, assim, comunidades/esferas sociais que não possuem acesso à internet;

- disseminar informações acerca da importância das áreas protegidas, tendo como molde a APA SUL RMBH e suas unidades de conservação;

- disponibilizar a Cartilha da Rede Socioambiental APA SUL RMBH para bibliotecas públicas, nas formas impressa e digital, de modo que seja um instrumento consultivo de múltiplos e fáceis acessos.

A Figura 3 apresenta o esboço do modelo conceitual do site para ilustrar a coerência de sua proposição em rela- ção aos objetivos previstos para o sistema de comunicação da Rede.

\section{Etapas do processo de construção do portal da Rede Socioambiental APA SUL RMBH}

As etapas do desenvolvimento serão apresentadas a seguir, tomando-se como referência o processo operacional e os objetivos a serem consolidados em cada uma.

\section{a) Pesquisa de dados}

Esta etapa foi destinada a levantar todos os dados necessários a fim de elaborar o banco de dados a ser disponibilizado virtualmente e traduzido para a Cartilha da Rede Socioambiental, tendo em vista a adequação ao perfil das partes interessadas e a disponibilização centralizada, antes difusa, de informações acerca da APA SUL RMBH. Esse processo cumpriu os seguintes passos:

- Pesquisa sobre modelos de comunicação ambiental e temas similares

Quais são as instituições responsáveis? Qual o seu perfil? Que sites possuem e quais as outras estratégias de comunicação utilizadas? Que estratégias são trabalhadas em seus sites? Que colocação possuem no cenário socioambiental? Quais os pontos fortes e os fracos de suas propostas?

Pretende-se oferecer, por meio da pesquisa, a informação acerca das lacunas e as perspectivas da sociedade preenchê-las, tendo a real noção da conjuntura em que se está entrando, além da busca pelo conhecimento efetivo das características necessárias para a implementação e a consolidação da Rede.

\section{- Pesquisa sobre o público-alvo}

Levantamento efetivo de todos os dados, com o público-alvo, que interessam para a estruturação da Rede Socioambiental APA SUL RMBH.

- Pesquisa sobre estratégias - Problematização

Levantar dados sobre as estratégias e informações a serem adotadas e a análise de sua utilização.

\section{b) Planejamento estrutural do site}

Após a pesquisa, realizada de modo participativo, definiu-se a estrutura do site de forma básica, conceitualmente. As definições abaixo explicitam, de forma geral, as etapas de estruturação do site:

\section{Conteúdo}

- Quantas páginas, links ou seções o site terá -

Etapa destinada ao desenvolvimento do perfil do site e temáticas abordadas. É importante acentuar que um site 


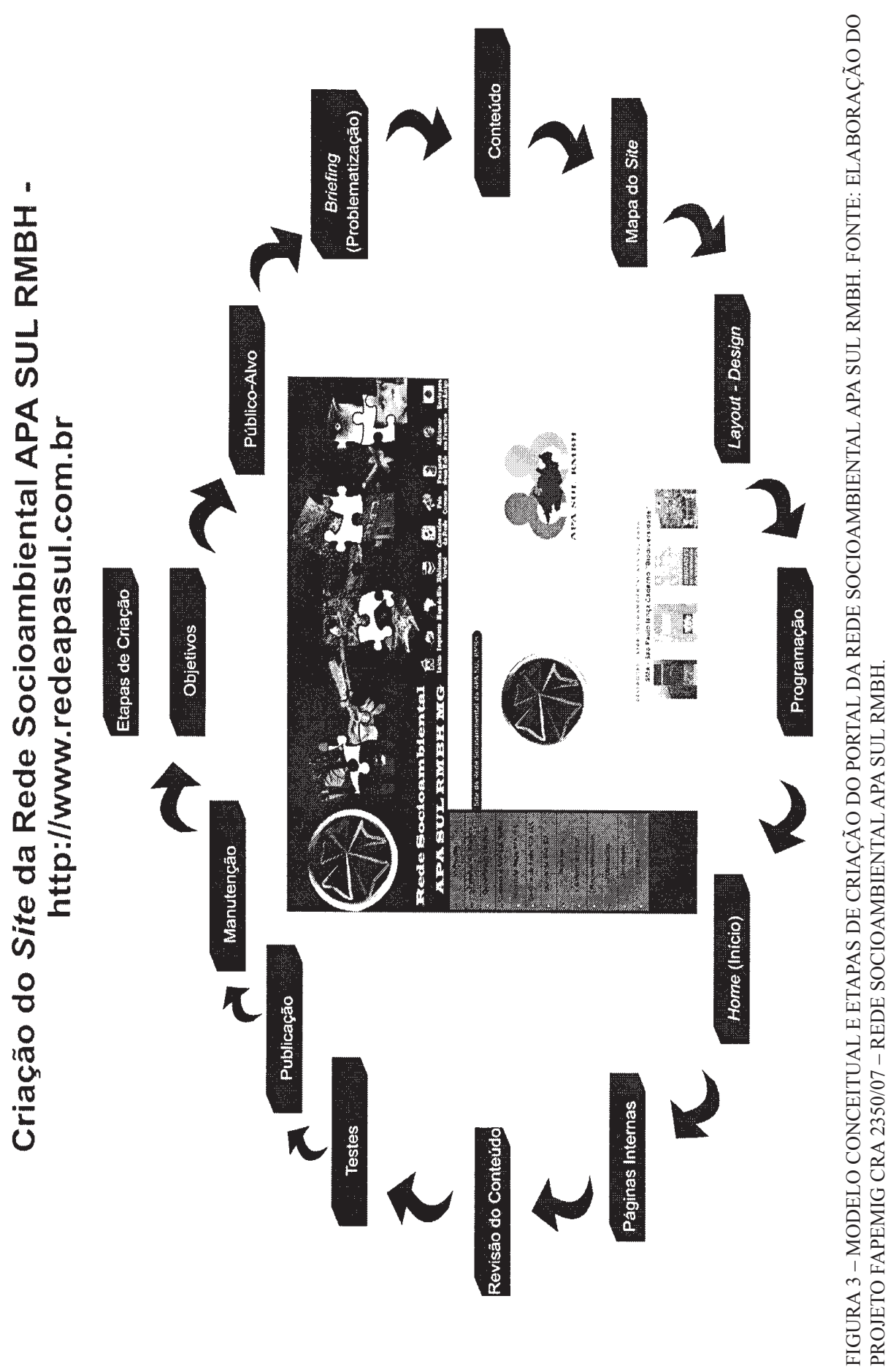


com poucos links não é necessariamente um site de pouco conteúdo; da mesma forma, um site repleto de links e seções não é, exatamente, um manancial de boas informações sobre determinado tema.

\section{- Mapa do site}

Estrutura básica da divisão dos links, com todas as páginas relacionadas com subdivisões dentro de um contexto maior. Muito mais do que menus com nomes de páginas escritos dentro, um mapa de site permite uma visualização global e visual do que se pretende, tornando fácil a visualização dos processos de alterações, aprovações e definições genéricas.

- Arquitetura da informação - Layout e programação

A arquitetura da informação perpassa pelo processo de separação do conteúdo, da condução do público-alvo pelo site, dos túneis de navegação, de estruturas lineares e não lineares de navegação, visando à criação de um site intuitivo, que ajude o visitante a encontrar tudo o que deseja, da forma mais direta e racional possível. Tal etapa é dedicada à utilização do conteúdo principal da web, de forma a extrair todo o seu potencial: o uso do hipertexto com o HTML, que permite a transferência de textos, figuras e outros arquivos por meio de suas tags.

- Textos principais - Webwriting

Método de escrita utilizado, que se baseia no ofício de escrever para a web, respeitando suas características: elaboração de textos curtos, rápidos, sintéticos e utilização do $L E A D$, com correção preliminar de possíveis erros ortográficos e gramaticais.

\section{- Cores}

A definição de cores de um site pode basear-se em vários aspectos, que vão desde as tonalidades padronizadas de uma instituição até o sentido conceitual que cada cor carrega por si própria. Existem teorias das cores genericamente aceitas, porém esse é um conceito que muda em cada ponto cultural, até mesmo entre diferentes públicos-alvo. É possível chegar a conjuntos de cores por meio de extenuantes pesquisas de mercado, avaliar como cada cor será aceita ou quais sentimentos provocarão em determinado perfil de público.

\section{- Linguagens}

Como falar com determinada faixa de público? Que termos devem ser empregados e evitados para atender a uma demanda tão ampla como os diversos segmentos envolvidos com a Rede Socioambiental APA SUL RMBH?

O marketing deve definir o tipo de linguagem a ser utilizada e a maneira de abordar o visitante durante sua visita às páginas do site. De modo geral, os textos utilizados buscaram enquadrar-se nas regras da simplicidade, da facilidade e da abrangência de entendimento.

\section{- Tipos de imagens}

Definição de que tipos de imagens serão utilizados de acordo com a linguagem empregada. As imagens podem possuir ora enquadramentos ousados, pouco usuais, ora ângulos tradicionais, comportados, "corretos".

- "Pré-site” em programas de apresentação

Quando necessário, pode-se montar a estrutura básica de navegação, de páginas, de links, utilizando-se uma ferramenta como o PowerPoint ou qualquer outra ferramenta voltada para a criação de apresentações. Essas apresentações foram utilizadas como guias na elaboração do processo criativo, tomando importantes decisões sobre a estruturação do site.

A partir do processo de desenvolvimento, a estruturação do site da Rede Socioambiental APA SUL RMBH buscou inserir em seu conteúdo uma diversidade abrangente acerca da temática envolvida com o cenário dessa unidade de conservação. As páginas do site foram construídas a partir de uma visão ampla e democrática do contexto da APA SUL RMBH, representadas por elementos que ilustram seus aspectos socioambientais, econômicos, políticos e culturais. O Portal da Rede pode ser acessado por meio do endereço eletrônico $<$ http://www.redeapasul.com.br $>$.

\section{A Cartilha da Rede Socioambiental APA SUL RMBH}

A Cartilha da Rede Socioambiental APA SUL RMBH, intitulada "APA SUL RMBH - Diversidade e Áreas Protegidas", busca retratar, de forma sintética, os propósitos específicos do projeto (Figura 4), justificando-os como uma oportunidade de consolidação, discussão e divulgação de um grande número de dados já existentes sobre essa área protegida. A versão completa da Cartilha supracitada pode ser encontrada no endereço eletrônico: $<$ http://www.redeapasul.com.br/cartilha_da_rede_apa_sul/ cartilha_da_rede_apa_sul.html $>$.

A reorganização e a atualização da Cartilha constituem-se em ferramentas para orientar ações, envolvendo a capacitação de agentes locais, definição de áreas de corredores ecológicos, integração de ecossistemas, tendências e cenários futuros de uso pela mineração e pela expansão urbana e distribuição da diversidade cultural. 


\begin{tabular}{|c|c|}
\hline SUBPROJETO & FUNÇOES/OBJETIVOS ESPECIFICOS \\
\hline $\begin{array}{l}\text { Subprojeto } 1 \\
\text { "Criaçąo e manutençăo do } \\
\text { Sistema de Informaçáo } \\
\text { Socioambiental daAPA Sul" }\end{array}$ & 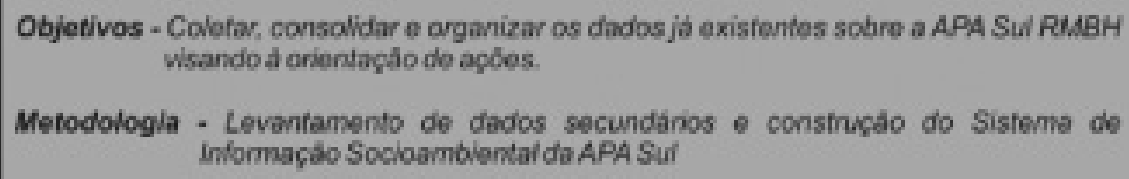 \\
\hline $\begin{array}{l}\text { Subprojelo } 2 \\
\text { "Formação de Agentes de } \\
\text { Desenvolvimento Local" }\end{array}$ & 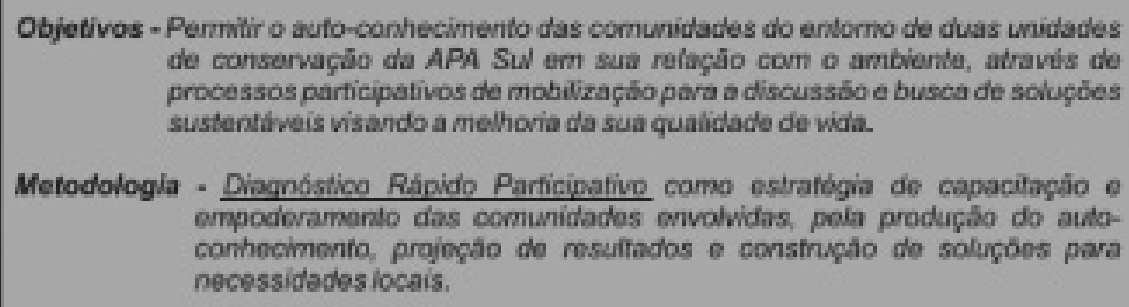 \\
\hline $\begin{array}{l}\text { Subprojeto } 3 \\
\text { "Criaça do Site da Rede APA } \\
\text { Sul RMBH" }\end{array}$ & 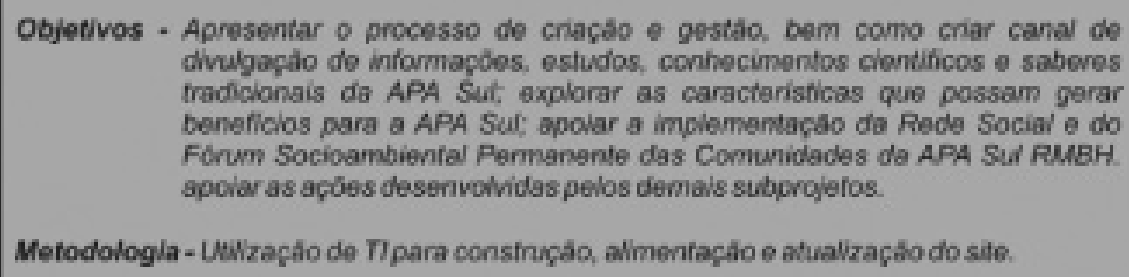 \\
\hline $\begin{array}{l}\text { Subprojeto } 4 \\
\text { Implementaçáo da Rede } \\
\text { Social APA Sul e do Fórum } \\
\text { Socioam-biental Permanente } \\
\text { APASul. }\end{array}$ & 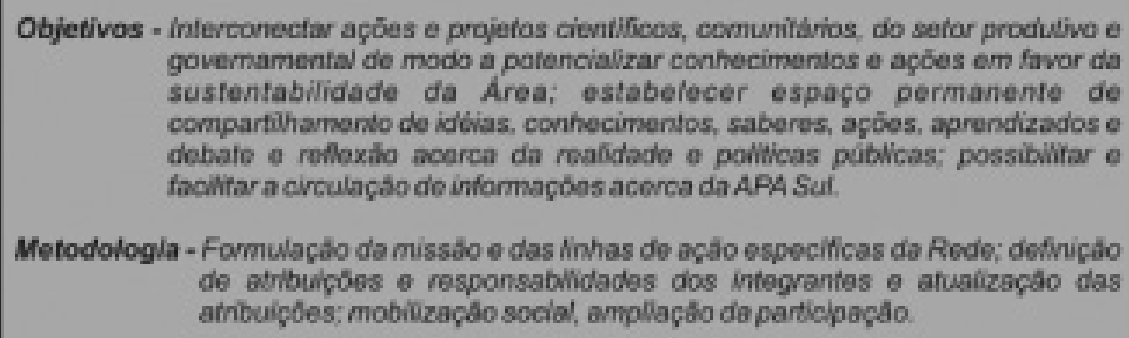 \\
\hline
\end{tabular}

FIGURA 4 - OBJETIVOS E FUNÇÕES DOS SUBPROJETOS DA REDE SOCIOAMBIENTAL APA SUL RMBH. FONTE: CARTILHA DA REDE SOCIOAMBIENTAL APA SUL RMBH. 
Nesse contexto, tal compêndio dispõe, em seu conteúdo, de uma identificação do público-alvo, como a sociedade civil, os poderes público e privado, as universidades e as ONGs, buscando utilizar uma linguagem fácil e acessível, mas que retrate, de modo fidedigno, o cenário diverso envolvido com a APA SUL RMBH.

A primeira parte da Cartilha foi delineada sucintamente e apresenta objetivos, metodologias, justificativas e perspectivas do Projeto da Rede Socioambiental APA SUL RMBH. A seção seguinte analisa o contexto das áreas protegidas inseridas ou relacionadas à região. Como passo inicial, foram explicitadas informações acerca da Reserva da Biosfera da Serra do Espinhaço, considerando a definição de uma Reserva da Biosfera, suas funções e justificativas, sua representatividade no território brasileiro e sua diversidade de bacias hidrográficas, ecossistemas, municípios integrados e seus aspectos socioambientais e econômicos, dando ênfase à região do Quadrilátero Ferrífero.

Em seguida, foram desenvolvidos capítulos sobre a APA SUL RMBH, iniciando-se com a definição de Área de Proteção Ambiental, seus objetivos, sua constituição e critérios de criação, segundo o SNUC. Segue, então, a contextualização do embasamento teórico, abordando-se o processo de criação da unidade de planejamento objeto de pesquisa, bem como suas implicações, enfatizando a proposta de Zoneamento Ecológico-Econômico, seu Conselho Consultivo, seus objetivos de gestão e os resultados já alcançados.

Reduzindo ainda mais as dimensões, chega-se, na Cartilha, ao contexto de unidades de conservação da APA SUL RMBH. São apresentados o Parque Estadual da Serra do Rola-Moça, o Parque Municipal das Mangabeiras e a Reserva Particular do Patrimônio Natural Santuário do Caraça, valorizando as origens e a criação, as finalidades, a localização, a hidrografia, a biodiversidade e a importância da conservação, além das ações antrópicas que a permeiam e as possíveis ações a serem realizadas nessas unidades de conservação.

O fechamento da Cartilha se dá pela demonstração do layout do site da Rede Socioambiental APA SUL RMBH, além da disponibilização de contatos para a busca por mais informações e esclarecimentos.

\section{Considerações finais}

O produto de comunicação ambiental requerido no Projeto da Rede Socioambiental APA SUL RMBH configu- ra-se como uma proposta coletiva que vislumbra não só a transmissão de informações e a contribuição educativa, mas também a integração e a socialização entre os segmentos envolvidos com o território da APA SUL RMBH. Com isso, almeja-se o delineamento de uma rede socioambiental atuante, cujos integrantes possam se comprometer com o futuro da unidade de conservação, agindo no enfrentamento dos problemas debatidos acerca dessa região.

O discurso de estruturação de tal modelo foi baseado em um ideal integrador, envolvido com a construção dos elementos de comunicação com as comunidades, mas não para as comunidades. A perspectiva de comunicação integrante emerge, então, no momento em que o ser social participa efetivamente da busca por dados, entende e identifica-se com os mecanismos de construção das ferramentas comunicativas, além de aproximar-se das demais realidades envolvidas com a conjuntura da unidade de conservação. Todos os membros do vasto e diverso cenário da APA SUL RMBH possuem seus relatos de vida referentes às experiências, aos hábitos, aos costumes e aos saberes tradicionais construídos por seus repertórios intrínsecos e pela convivência com o outro e adjuntos ao ambiente que permeia seu contexto de vida.

Objetivou-se, a partir dessas premissas, a estruturação de um site que, além de incorporar em seu conteúdo informações, estudos, conhecimentos científicos e saberes tradicionais da APA SUL RMBH, atuasse também como uma ferramenta de conexão por meio do diálogo, do encurtamento de distâncias e de intercâmbios virtuais, com o fortalecimento e mobilização das esferas envolvidas: sociedade civil, universidades, empresas privadas e poder público em todas as suas esferas.

Para se constituírem, o site e a Cartilha da Rede Socioambiental APA SUL RMBH incorporaram tecnologias apropriadas para destacar a importância do debate sobre conhecimentos, conservação e usos de recursos ambientais, comportando bases de dados e links institucionais para a interação ampliada com o público. A consistência dessa ferramenta deve contribuir para consolidar uma imagem pública da Área de Proteção Ambiental como unidade de planejamento territorial efetiva e como objeto essencial de conservação, tendo em vista sua inserção em região mínero-metalúrgica. Acredita-se que a difusão de conhecimentos - ciência, tecnologia e informações - sobre condições socioambientais, serviços, centros de pesquisas, bibliotecas virtuais especializadas, eventos, iniciativas públicas, privadas ou da sociedade civil, mais do que estruturar a rede 
de relações, pode contribuir com o ideário da conservação ambiental.

A proposta da Rede Socioambiental APA SUL RM$\mathrm{BH}$, tendo como enfoque suas estratégias de comunicação ambiental para mobilização socioparticipativa, não deve ser entendida como uma harmonização forçada de divergências e conflitos dentro e entre os diversos segmentos envolvidos,

\section{Referências}

AMARAL, V. Desafios do trabalho em rede. 2004. Disponível em: $<$ http://www.repea.org.br/index.php/conceitual/redes/84desafios-do-trabalho-em-rede>. Acesso em: 18 jul. 2010.

BERNA, V. S. D. Comunicação Ambiental para a parceria. 2002. Disponível em: <http://www.escritorvilmarberna.com. br/artigos/comunicacao-ambiental>. Acesso em: 15 jan. 2010.

CAMPOS, M. K. S. A Comunicação Ambiental no Brasil e o potencial de aplicação da norma ISO 14063. In: SEMINÁRIO INTERNACIONAL "TENDÊNCIAS DA INTERNATIONAL FOR STANDARDIZATION - ISO EM NORMALIZAÇÃO AMBIENTAL INTERNACIONAL E AS AÇÕES NO BRASIL. FIESP, São Paulo. 2007.

CASTELLS, M. A sociedade em rede. São Paulo: Paz e Terra, 2000.

DOWNING, J. D. H. Mídia radical: rebeldia nas comunicações em movimentos sociais. São Paulo: Senac, 2002.

ELHAJJI, M.; REIS, J. M. da S. P.; ANDREONI, M. Introdução à Comunicação Ambiental. In: CONGRESSO BRASILEIRO DE CIÊNCIAS DA COMUNICAÇÃO, 31. Intercom Sociedade Brasileira de Estudos Interdisciplinares da Comunicação. Natal. 1 a 6 de setembro de 2008. Anais...

FARIA, A. L. G. de. Ideologia no livro didático. São Paulo: Cortez, 2000. $101 \mathrm{p}$.

GALEANO, E. Entrevista de Eduardo Galeano a Marcelo Salles para o jornal impresso Fazendo Média, 28 de dezembro de 2005. Jornal Fazendo Média, 2005. Disponível em: < http:// www.fazendomedia.com/novas/entrevista281205.htm>. Acesso em 10 mar. 2009.

GOOTHUZEM, R. Comunicação Ambiental e dogma. Envolverde - Revista Plurale, 2009. Disponível em: <http:// envolverde.ig.com.br/materia.php? $\operatorname{cod}=61242 \&$ edt $=34>$. Acesso em: 10 mar. 2010. mas como uma oportunidade de construção conjunta de um espaço intersetorial democrático, que priorize o diálogo, o intercâmbio de informações, o encurtamento de distâncias e eventuais parcerias, respeitando os saberes tradicionais locais, a autonomia e a realidade inerente a cada representação da Rede.

INOJOSA, R. M. Movimento Municípios Saudáveis: aspectos legais relacionados à operacionalização e implementação do planejamento intersetorial. In: SEMINÁRIO NACIONAL MOVIMENTOS SAUDÁVEIS: ASPECTOS CONCEITUAIS, LEGAIS E OPERACIONAIS. São Paulo, Faculdade de Saúde Pública/USP, 1999. Anais...

IBGE - INSTITUTO BRASILEIRO DE GEOGRAFIA ESTATÍSTICA. Geociências. 2005. Disponível em: <ftp:/geoftp. ibge.gov.br/mapas/malhas-digitais/municipios_2005/E500>. Acesso em: 23 maio 2008.

ISO 14063. Comunicação Ambiental - Diretrizes e exemplos. 2006.

JACOBI, P. R. Meio ambiente e redes sociais: dimensões intersetoriais e complexidade na articulação de práticas coletivas. RAP - Revista Brasileira de Administração Pública, v. 34, n. 6, p. 131-158, 2000.

MÁXIMO, M. E. Novos caminhos de socialização na Internet: um estudo das listas eletrônicas de discussão. In: REUNIÓN DE ANTROPOLOGÍA DEL MERCOSUR, 3., 1999, Posadas/ AR. Resúmenes. Posadas: Universidad Nacional de Misiones (UM), p. 7, 1999.

MORAES, D. de. Comunicação alternativa, redes virtuais e ativismo: avanços e dilemas. Revista Eptic On-Line (UFS), v. IX, p. 1-20, 2007.

MOREIRA, M. S. Estratégia e implantação do Sistema de Gestão Ambiental. Belo Horizonte: Editora de Desenvolvimento Gerencial, 2001.

MOUSINHO, P. Redes. In: FERRARO JUNIOR, L. A. (Org.). Encontros e caminhos: formação de educadoras(es) ambientais e coletivos educadores. Brasília: MMA - Departamento de Educação Ambiental, v. 2, p. 299-312, 2007.

PICHELLI, K. R.; SUZINA, A. C. A questão ambiental e o discurso informativo: formas de mobilização social. In: SE- 
MINÁRIO CELACOM, São Bernardo do Campo. Celacom, 2005. Anais...

RABELO, D. C. Comunicação e mobilização na agenda 21 local. Vitória/ES: EDUFES/FACITEC, 2003.

RAMOS, M. P. Apoio social e saúde entre idosos. Revista Sociologias, v. 4, n. 7, p. 162-163, 2002.

RHEINGOLD, H. A comunidade virtual. Lisboa: Gradiva Publicações, 1996.

SANTOS, A. N.; ALVES, F. B.; SANTOS, J. Pensar a integração social do sujeito para além das legislações no campo Educação Especial. In: SIMPÓSIO INTERNACIONAL "O ESTADO E AS POLÍTICAS EDUCACIONAIS NO TEMPO PRESENTE", 4., 2008. Programa de Pós-Graduação em Educação da Universidade Federal de Uberlândia. Uberlândia - Minas Gerais. p. 82-98, 2008. Anais...

SANTOS, A. D. (Org.). Metodologias participativas: caminhos para o fortalecimento de espaços públicos socioambientais. IEB - Instituto Internacional de Educação do Brasil. 1. ed. São Paulo: Peirópolis, v. 1, 2005. 185 p.

SCHERER-WARREN, I. Movimentos em cena... E as teorias por onde andam? Revista Brasileira de Educação, n. 9, p. 16-29, 1998.
SILVA, L. M. Comunicação, mobilização e mudança social. In: MONTORO, T. S. (Org.). Série Mobilização Social, Comunicação, Cultura, Cidadania e Mobilização Social. Brasília/ Salvador: UnB, v. 2, 1997. 29 p.

SILVA, S. C. P. da. Integração social da tecnologia: uma esfera social da educação. In: SEMINÁRIO INTERNACIONAL - CIÊNCIA E TECNOLOGIA DA AMÉRICA LATINA: A UNIVERSIDADE COMO PROMOTORA DO DESENVOLVIMENTO SUSTENTÁVEL, 3. Coordenadoria de Relações Institucionais e Internacionais/Unicamp, Campinas, 2006. (site). Anais..

SOARES, D. Educação escolar e os meios de comunicação. 2005. Disponível em: $<$ http://www.portalgens.com.br $>$. Acesso em: 04 maio 2010.

TORO, J. B.; WERNECK, N. M. D. Mobilização social: um modo de construir a democracia e a participação. Belo Horizonte: Autêntica, 2004.

VALARELLI, L. L. Gestão do Terceiro Setor: uma noção ampliada de captação de recursos. Instituto Rits: 2001. Disponível em: <http://www.rits.org.br>. Acesso em: 14 maio 2010.

Recebido em agosto de 2010.

Aceito em outubro de 2010. Publicado em dezembro de 2010. 